\title{
Violencia armada del "EPP" en el norte paraguayo desde las voces disidentes y a cara descubierta*
}

\section{Armed violence of the "EPP" in the north of Paraguay from dissident voices and uncovered faces}

\author{
Hugo Pereira $^{1} \odot$
}

\begin{abstract}
Resumen
Los hechos de violencia registrados en el norte paraguayo desde el año 2008, atribuidos a una supuesta organización guerrillera conocida como "Ejército del Pueblo Paraguayo", a la que se identifica con la sigla "EPP", han sido relatados de manera hegemónica desde la perspectiva de la versión oficial amplificada por los grandes medios de comunicación. En un más de una década de violencia armada se han registrado algunos episodios que han configurado la aparición de crisis que posibilitaron la irrupción en el debate público de voces que fueron marginadas en todos estos años del relato oficial y de las reflexiones de analistas conservadores y progresistas, incluso de ciertos referentes de organizaciones de Derechos Humanos. Esas voces disidentes, de pobladores campesinos e indígenas del norte paraguayo, se desmarcan de la violencia del "EPP". Lo hacen sin esconderse en el anonimato, a cara descubierta. Todo esto coloca en entredicho las afirmaciones que aseguran la existencia del involucramiento de la población con el "grupo insurgente" y el supuesto silencio al que se llama para evitar represalias de una "guerrilla" a la que en realidad rechaza, lo que además hace inviable el apoyo político que toda insurgencia requiere para alcanzar sus objetivos.
\end{abstract}

Palabras clave: "EPP”, violencia armada, guerrilla, voces disidentes, norte paraguayo.

\begin{abstract}
The acts of violence registered in northern Paraguay since 2008, attributed to an alleged guerrilla organization known as the "Army of the Paraguayan People", which is identified with the acronym "EPP", have been reported in a hegemonic way from the perspective of from the official version amplified by the mainstream media. In more than a decade of armed violence, there have been some episodes that have configured the appearance of crises that made possible the irruption in the public debate of voices that were marginalized in all these years from the official account and from the reflections of conservative and progressive analysts, even of certain referents of Human Rights organizations. Those dissident voices, of peasant and indigenous inhabitants of the Paraguayan north, distance themselves from the violence of the "EPP”. They do it without hiding
\end{abstract}

1 Consejo Nacional de Ciencia y Tecnología (CONACYT). Asunción, Paraguay.

* Cada vez que el autor toma la palabra en el artículo coloca la sigla "EPP" entre comillas a fin de tomar distancia de la versión hegemónica sobre la supuesta guerrilla que opera en el norte paraguayo.

Correspondencia:

hugopereirac@gmail.com

Recibido:

28 de agosto de 2021

Aceptado:

5 de octubre de 2021

Doi:

https://doi.org/10.54549/ky.6e.2021.120

\section{(c) (7)}

Artículo publicado en acceso abierto bajo la Licencia Creative Commons.

Cita:

Pereira, H. (2021). Violencia armada del "EPP" en el norte paraguayo desde las voces disidentes y a cara descubierta. Kera Yvoty: reflexiones sobre la cuestión social, 6(número especial), $\mathrm{x}-\mathrm{y}$. https://doi.org/10.54549/ ky.6e.2021.120 
in anonymity, with an open face. All this calls into question the assertions that ensure the existence of the population's involvement with the "insurgent group" and the supposed silence that is called upon to avoid reprisals from a "guerrilla" that it actually rejects, which also makes it unfeasible the political support that every insurgency requires to achieve its objectives.

Keywords: “EPP”, armed violence, guerrilla, dissident voices, northern Paraguay.

\section{Introducción}

La credibilidad y la aceptación del relato oficial implican, al decir de Michael Pollak, un intenso trabajo de organización para superar el simple montaje ideológico, el cual es precario y frágil. Solo así puede configurarse un fondo común de referencias que constituya una memoria nacional. Frente a ésta última, las memorias clandestinas, inaudibles y disidentes, aquellas de grupos sociales excluidos y marginados, que operan subversivamente en el silencio, afloran desde lo subterráneo al espacio público en momentos de crisis, pasando así a la contestación al exceso de discursos oficiales y a la reivindicación (Pollak, 2006). El relato oficial se constituye en la versión que adopta el Estado y el poder fáctico. Sin embargo, no existe una única competencia entre el discurso hegemónico y el contestatario. Al mismo interior de las mismas organizaciones de derechos humanos se encuentran también divergencias, lo que explica la existencia de varias organizaciones con posturas y opiniones distintas (Oberti \& Pittaluga, 2016).

Lo anterior puede verse con claridad en el caso del norte paraguayo donde opera supuestamente un grupo subversivo conocido como "Ejército del Pueblo Paraguayo" (EPP). El Instituto de Altos Estudios Estratégicos (IAEE) ${ }^{1}$ considera "académicamente" al "EPP" una "guerrilla". Así se estudia en los cursos de postgrado del IAEE en un módulo titulado "Defensa

1 El IAEE fue creado durante el período de la dictadura de Alfredo Stroessner a través de la Ley $N^{\circ} 9$ del 27 de agosto de 1968 con la entonces denominación de Colegio Nacional de Guerra. Depende directamente del presidente del Consejo de Defensa Nacional, quien es al mismo tiempo el presidente de la república y comandante en jefe de las Fuerzas Armadas. interna" ("En el IAEE se estudia que el EPP es una organización guerrillera", 2020). La imposibilidad de acabar con el "EPP" tiene como explicación principal de los grupos conservadores de Paraguay el apoyo de la población al supuesto grupo insurgente (Pereira, 2016). Una explicación en la que coinciden determinados integrantes de organizaciones de derechos humanos. En el año 2017 se daban a conocer los resultados de un estudio académico desarrollado sobre la naturaleza política del "EPP" desde parte de ese sector. Juan Martens, abogado defensor de derechos humanos, director del equipo de investigación que realizó dicho trabajo, declaraba a la prensa empresarial, que dio amplia difusión a los resultados de su investigación, que ciertas comunidades campesinas del norte paraguayo se habían convertido en "santuarios" o "zonas de confort" del "EPP”, grupo que logra la adhesión de la población mediante el pago a familias pobres de su zona de influencia. Decía además que el "EPP” paga sus estudios a los jóvenes, indicando textualmente: "Hemos detectado ciertos colegios donde hay profesores afines al EPP y que actúan como captadores de estudiantes" ("EPP: Pagan estudios de jóvenes", 2017).

En un artículo académico publicado en el 2017, Martens comprometía aún más a las organizaciones sociales. Señalaba en ese trabajo que el "EPP" no solo había reclutado a varios integrantes de esas agrupaciones, sino que utiliza los mismos recursos de las organizaciones en su provecho. En el documento académico aclara que las conversaciones que el equipo investigador mantuvo con integrantes de las comunidades campesinas en las que supuestamente actúa el grupo "guerrillero" no se realizaron con consentimiento 
informado. Según Martens ello fue así para proteger a los investigadores de su equipo, quienes incluso no se identificaron como tales en el terreno de estudio. Varias voces en off justifican la argumentación del abogado defensor de derechos humanos a lo largo de su artículo en el que concluye que la población rural coopera con el grupo “insurgente" "EPP" (Martens, 2017).

También algunos analistas identificados con posiciones políticas progresistas no piensan muy diferente, señalando que el "EPP” es una organización revolucionaria que lucha a favor de grandes mayorías populares excluidas, como campesinas e indígenas (Carbone, 2020). Algunos incluso creen que para muchas familias del norte paraguayo "sin esperanzas ni futuro", no sería "lunáticamente radical" el terrorismo como una manera de solución a la situación de inequidad social que padecen, indicando que cierta parte de la población le brinda protección y apoyo logístico al "EPP” (Boccia, 2020). Otros concluyen que el sistema político excluyente de Paraguay, liderado por élites que han bloqueado la posibilidad de realizar una reforma agraria en el país más desigual de acceso a la tierra en el mundo, se constituye en una de las causas de la insurgencia rural del Paraguay (Nickson, 2019).

Todas esas afirmaciones vinculan e involucran a la población rural del norte paraguayo con la violencia "guerrillera" del "EPP". En ellas se puede advertir una consideración común que simplifica la realidad del norte paraguayo como ha sucedido en otros casos, que la violencia es ejercida por la población rural, es decir causada por la misma víctima (Malamud, 2000). Sin embargo, excluyen del análisis las voces de dicha población. Tal como ha ocurrido en otras indagaciones sobre violaciones de derechos humanos, ciertos aspectos, algunos claves para el esclarecimiento, no son considerados en la búsqueda de la verdad (Hayner, 2009).

\section{Aspectos metodológicos}

Las descripciones y afirmaciones sobre la realidad no sólo informan sobre ella sino que la constituyen, lo cual significa que el código no es informativo ni externo a la situación que se describe (Guber, 2001). El Estado tiene el poder de nombrar, identificar, categorizar, o sea indicar qué es qué y quién es quién (Brubaker \& Cooper, 200). Las identidades son construidas dentro del discurso y no fuera de él en un contexto histórico e institucional mediante "estrategias enunciativas específicas" (Hall, 2003, p.18), en el marco de relaciones de poder en el que son posibles ciertos modos de identificación mientras que otros quedan excluidos (Grimson, 2011, p.179).

La identificación de sectores sociales como "campesinos", "pueblos originarios", "trabajadores rurales" depende de quién enuncie esas nominaciones, es decir: “¿qué son, para quién, para qué? (Grimson et al., 2011, p. 15). La nominación se realiza desde una posición de poder que designa a los habitantes de un territorio, que autoriza y prohíbe ciertas identidades o nombres.

Los órganos de seguridad del Estado paraguayo y la Fiscalía afirman que en el norte del país las fuerzas regulares se enfrentan a una guerrilla, es decir, a un grupo alzado en armas que pretende tomar el poder a través de las armas. La versión es amplificada por los grandes medios de comunicación de manera constante, lo que permite identificar una línea discursiva del relato que se realiza sobre la violencia en la zona. Un aspecto importante del discurso oficial y mediático, validado incluso por ciertos sectores progresistas y referentes de organizaciones de Derechos Humanos, es el que vincula a la población campesina e indígena con la "violencia guerrillera". Debe precisarse sin embargo que la violencia puede o no ser guerrillera, puede o no perseguir un objetivo de transformación radical de una sociedad. La guerrilla apunta a derrotar al gobierno y redefinir las relaciones de poder, mientras que el paramilitarismo busca mantener el statu quo (Pizarro, 2004).

El relato sobre la violencia en el norte paraguayo es hegemónico, es oficial 
y mediático. Sin embargo, ¿qué piensa la población del norte al respecto? Este trabajo se propuso contrastar la versión dominante sobre la violencia instalada en el norte del Paraguay con la opinión de actores sociales del departamento de Concepción. Para lograr dicho objetivo se ha realizado un análisis de documentos oficiales y no oficiales relacionados a la temática estudiada. Además, se ha examinado el mecanismo de construcción discursiva del relato de la Fiscalía, la Policía Nacional, las Fuerzas Armadas y otros referentes de instituciones estatales, académicos y actores políticos, difundida ampliamente por los grandes medios de comunicación. Esa línea discursiva fue contrastada con la de pobladores y pobladoras del norte paraguayo cuyas voces fueron analizadas para tener una comprensión de la explicación que tienen sobre lo que ocurre en su territorio.

\section{La irrupción del "EPP" que frustró la lucha de sus "representados"}

El 14 de marzo del 2008 las portadas de los principales periódicos, los espacios informativos de la radio y la televisión de Paraguay hacían referencia a un acontecimiento ocurrido dos días antes. El 12 de marzo de ese año, según la versión periodística, un grupo armado quemó en el norte paraguayo el galpón del establecimiento de un terrateniente de nacionalidad brasileña. La pérdida generada por el incendio provocado en el lugar, donde se encontraban tractores, un camión y otras máquinas agrícolas, habría rondado los cuatrocientos mil dólares americanos. En la escena fue dejado un panfleto en el que el "Ejército del Pueblo Paraguayo" (EPP) se atribuía el atentado. Fue la primera vez que la opinión pública paraguaya escuchó hablar del "EPP". El ataque, según el documento impreso hallado, era una venganza y al mismo tiempo una declaración de guerra contra los efectos causados a la salud de la población y al medioambiente de la comunidad campesina Kurusu ${ }^{2}$ de Hierro por las fumigaciones realizadas en los cultivos de soja de la propiedad del brasileño. "Tierra a los campesinos paraguayos. Quienes matan al pueblo con agrotóxicos pagarán de esta manera", se leía en el panfleto del "EPP" ("Queman tractores y galpón en estancia", 2008).

El productor sojero acusó a sus vecinos campesinos de estar vinculados al ataque. El fiscal de la zona afirmó que las evidencias apuntaban a un grupo guerrillero que tendría relación con organizaciones campesinas interesadas en acceder a las tierras del propietario del establecimiento ("Investigan a supuesto grupo guerrillero", 2008). Es que la noticia sobre la quema provocada fue difundida ampliamente un día antes de una reunión que podría ser clave para llegar a un acuerdo entre el terrateniente brasileño y los campesinos respecto a unas 700 hectáreas de tierra que serían parte de un excedente fiscal que estaría irregularmente incorporado al terreno del empresario sojero.

Los líderes de la comunidad campesina, además de negar la acusación que relacionaba a los pobladores de Kurusu de Hierro con el atentado "guerrillero", señalaron que en realidad la quema podría tratarse de un auto-atentado del mismo productor brasileño para frustrar la realización del encuentro que pudo haber logrado que las tierras fiscales sean entregadas a sujetos de la reforma agraria. Por otro lado, afirmaron que la acusación se trataba de una represalia a las denuncias realizadas contra la pulverización en el sojal sin las debidas medidas de protección medioambiental, que producía daños a la salud de la población, arruinaba los cultivos de la agricultura familiar además de provocar la muerte de animales. Dijeron que no era la primera vez que el sojero los acusaba de delitos que no cometieron.

En efecto, en junio del 2007 el sojero brasileño denunció a sus vecinos

2 Palabra guaraní que significa cruz. 
campesinos de un hecho supuestamente ocurrido cuatro meses antes, febrero de ese año. Afirmó que entonces robaron caballos y ganado vacuno de su establecimiento, agregando al momento de la ratificación de su denuncia que los campesinos ya habían cometido varios robos de ganado, delitos económicos y robo agravado. La acusación no pudo sostenerse en el juicio porque en la propiedad no había animales, por lo que no podía robarse algo inexistente. La Fiscalía pidió la desestimación de la causa y el juez falló a favor de los denunciados3. Al mes siguiente de la primera denuncia que terminó siendo desestimada, el sojero volvió a denunciar a los campesinos en julio del 2007, esa vez por robo de maíz y herramientas del taller del establecimiento, un hecho que habría ocurrido dos meses antes. La causa terminó nuevamente siendo desestimada por la Justicia ${ }^{4}$. En una tercera denuncia el terrateniente brasileño se refirió a un hecho que habría ocurrido en noviembre del 2007. Señaló que en dicha oportunidad unos cincuenta campesinos, en su mayoría ebrios, al parecer drogados, y armados con puñales y garrotes, atacaron violentamente su estancia e intentaron quemar un tractor fumigador. Una vez más la Justicia desestimó la causa porque no se pudo probar la vinculación entre los delitos supuestamente cometidos y los denunciados 5 .

Las denuncias de los pobladores de la comunidad campesina de Kurusu de Hierro contra la fumigación irregular de agroquímicos fueron sistemáticas desde el

\footnotetext{
3 Auto Interlocutorio $\mathrm{N}^{\circ}$ 646/2008. Causa Requerimiento de desestimación de denuncia en la Causa Fiscal No 2007-0001043: Juan de la Cruz Cristaldo y otros sobre abigeato en la estancia Santa Herminia, Paso Tuya, Horqueta.

4 Auto Interlocutorio $\mathrm{N}^{\circ}$ 198/2008. Demetrio Alvarenga Ortiz y otros sobre robo agravado y asociación criminal en Paso Tuya. Expediente $\mathrm{N}^{\circ} 38$. Folio $\mathrm{N}^{\circ}$ 05, año 2007.

5 Auto Interlocutorio $\mathrm{N}^{\circ}$ 256/2008. Demetrio Alvarenga y otros sobre hurto agravado en banda y otros en Kuruzu de Hierro de esta jurisdicción. Expediente $\mathrm{N}^{\circ} 85$. Folio 07, año 2007.
}

año $2006^{6}$. En respuesta a ello la Fiscalía del Medio Ambiente se constituyó en mayo del 2007 en el establecimiento del sojero brasileño y constató la ausencia de una barrera viva, una fila de árboles de dos metros de alto por cinco metros de ancho que impida el paso de los agroquímicos fumigados hacia las casas de las familias vecinas de la zona ("Culpan a brasileño por intoxicación”, 2007). En la oportunidad el fiscal emplazó al propietario de las tierras por 30 días para dar cumplimiento a la medida establecida en la legislación nacional. En noviembre de ese mismo año la Secretaría del Ambiente del gobierno departamental de Concepción, en cuya jurisdicción se encuentra la comunidad, realizó una intervención y constató delitos ambientales que fueron comunicados a la Fiscalía7, la que imputó al sojero. A partir de la imputación realizada por el Ministerio Público, un juez de la zona ordenó la suspensión de la fumigación en el sojal hasta tanto se desarrolle la barrera viva ${ }^{8}$. En enero del 2008 se constituyó en la hacienda el Servicio Nacional de Calidad y Sanidad Vegetal y de Semillas (SENAVE), ente público dependiente del gobierno central que constató la misma irregularidad y exigió el mismo cumplimiento de lo establecido en la ley ambiental9.

La irrupción del "EPP" frustró la posibilidad de una negociación que posibilitaría que una fracción de tierras sea destinada a familias campesinas ${ }^{10}$ además

6 Desde el período productivo 2006/2007 los cultivos de soja se expandieron de manera creciente y constante sobre el territorio agrícola del departamento de Concepción, llegando a ocupar en los siguientes períodos más de la mitad de la superficie agrícola total.

7 Acta de intervención $N^{\circ}$ 3705. Secretaría del Ambiente, Concepción, 20 de noviembre de 2007.

8 Expediente $N^{\circ} 85 / 2007$, Causa: Nabor Both sobre delitos contra el medio ambiente en la Estancia Santa Herminia.

9 Acta de intervención. Servicio Nacional de Calidad y Sanidad Vegetal y de Semillas, Concepción, 18 de enero de 2008.

10 La desigualdad en el acceso a la tierra en el departamento de Concepción tiene uno de los niveles más altos a nivel mundial (Pereira, 2016). 
de desacreditar la lucha de la comunidad, lo que fue leído por la Organización Campesina del Norte $(\mathrm{OCN})$ como una directa persecución a los pobladores de Kurusu de Hierro por parte del productor sojero, quien con la quema se estaba colocando en papel de víctima cuando en realidad era victimario según la organización.

Denunciamos, una vez más, la violenta y descarada persecución a los pobladores de Kuruzu de Hierro, por parte del sojero Brasileño Nabor Both, en complicidad con autoridades fiscales y policiales [...] los crímenes cometidos por éste Brasilero en contra de la vida, el medio ambiente y los recursos naturales son colosales y prácticamente irrecuperables; como el daño a la vida de los niños, la contaminación de recursos hídricos y la depredación de bosques y suelos [...] Exhortamosa todas las organizaciones fraternas del departamento [...] a pronunciarse sobre la situación de los compañeros/as de la mencionada comunidad con el fin de aunar esfuerzos contra el ataque del sojero brasileño en complicidad con autoridades, utilizando el pretexto de ser "victima"(Organización Campesina del Norte, 17 de marzo de 2008, comunicado a la opinión pública).

\section{Proceso de silenciamiento de las voces campesinas y configuración discursiva del agricultor "guerrillero"}

A partir de lo ocurrido en marzo del 2008 las voces del campesinado organizado del norte paraguayo empezaron a ser sepultadas por las líneas discursivas marcadas por los grandes medios de comunicación de Paraguay. Los principales periódicos paraguayos, caracterizados por su apoyo al agronegocio, sector económico que no solo defienden sino del que son parte sus propietarios (Segovia, 2010), y por la argumentación criminalizadora de sus notas editoriales respecto a las organizaciones campesinas (Sánchez, 2009), profundizaron la vinculación de la violencia "guerrillera" con la población rural. Un ejemplo de ello es un artículo del diario $A B C$ Color que explícitamente señalaba que las organizaciones "izquierdistas", las que "contarían con el apoyo de los pobladores", crean un "ambiente de terror en la zona norte" ("Organizaciones izquierdistas crean ambiente de terror", 2008).

Las voces de funcionarios estatales y líderes políticos que refuerzan el vínculo "guerrilla" y campesinado fueron amplificadas en las diferentes notas periodísticas. Las declaraciones fueron identificando a los supuestos integrantes del "EPP" como combatientes que "simulan ser campesinos", al decir de una agente del Ministerio Público del norte paraguayo ("Fiscala Ruiz asegura saber dónde están los guerrilleros", 2011). Según una ex diputada, también del norte de Paraguay, está demostrado que "de día son simples labriegos y de noche son integrantes del EPP" ("Diputada asegura que miembros del EPP de día son simples labriegos", 2014). Una senadora afirmó que los guerrilleros "están mimetizados con la población", lo que significa que el "mismo campesino que está labrando la tierra, ese puede ser uno del EPP" ("Gusinky dice que", 2015). Lo anterior fue mejor especificado por un fiscal de la Unidad Antisecuestro de Concepción al señalar que los integrantes "semiprofesionales son agricultores de día y guerrilleros de noche" ("Fiscal culpa a pobladores por ataque contra comisarías", 2015).

Las oposiciones y cuestionamientos de los lugareños a las primeras medidas de seguridad implementadas, como la construcción de una comisaría en Kurusu de Hierro, con una edificación y dotación bastante superiores a los puestos policiales de las áreas rurales de Paraguay, fue considerada por los grupos políticos y económicos hegemónicos como provenientes de sectores "izquierdistas" 
("Grupo de izquierda se opone a la construcción de comisaría", 2008). La construcción de la comisaría contó con el apoyo de terratenientes norteños. Desde el gobierno se afirmó que los operativos de seguridad seguirían adelante, desoyéndose las denuncias de torturas realizadas a pobladores campesinos por parte de las fuerzas estatales para adjudicarle a un líder de la comunidad y otros habitantes la autoría de la quema de un puesto militar del norte paraguayo ("Comisaría en la conflictiva Kurusu de Hierro", 2009), quema también atribuida al "EPP".

Entre los años 2009 y 2010 se ejecutaron cinco operativos de seguridad, uno de ellos durante el primer estado de excepción establecido para el norte paraguayo veintiún años después de la caída de la dictadura". Los operativos involucraron esos años a más de cinco mil efectivos policiales y militares. Al año siguiente, 2011, se implementó otro estado de excepción que se prolongó por sesenta días, el doble del tiempo que el primero, con el mismo objetivo de acabar con la "guerrilla" y con el mismo nulo resultado (Pereira, 2014; Irala \& Pereira, 2016).

En el año 2013, apenas siete días después del ascenso a la presidencia de la república del empresario Horacio Cartes, a propuesta suya, y tras solo unas dos horas de debate, el Congreso Nacional aprobó y el presidente promulgó en tiempo récord la modificación de la ley $\mathrm{N}^{\circ} 1337 / 1999$ de Defensa Nacional y Seguridad Interna, habilitando la participación de las Fuerzas Armadas en la seguridad interna del país, competencia exclusiva, según la Constitución Nacional, de la Policía. Los opositores a la modificación de la ley fueron señalados por la nota editorial del diario $\mathrm{ABC}$ Color como afines al "bolivarianismo

11 El primer estado de excepción para combatir al "EPP" fue establecido del 24 de abril al 24 de mayo del 2010. El operativo desarrollado en ese marco fue denominado por el gobierno "Py’a guapy", expresión en guaraní que en el contexto de la lucha contra la violencia "guerrillera" hace referencia a la idea de pacificación. chavista" ("La doble cara de los bolivarianos vernáculos", 2013). Poco después de la modificación de la mencionada ley, Cartes creó la Fuerza de Tarea Conjunta (FTC), integrada por militares y policías, para "combatir" al "EPP", lo que en los hechos instaló un estado de excepción permanente (Pereira, 2016). La FTC, integrada por más de mil efectivos ${ }^{12}$, le cuesta al contribuyente paraguayo alrededor de un millón de dólares al mes ("Pedirán informe sobre gasto", 2020; "Elevado presupuesto de la FTC", 2020).

Ante el fracaso permanente para acabar con el "EPP" desde el 2008 en adelante, se escucharon sugerencias extremas como lanzar bombas a las zonas campesinas en las que se encuentran los "guerrilleros", un precio que según una legisladora integrante de la Comisión de Derechos Humanos del Senado es necesario pagar, similar al proceso de extirpar un cáncer en el que también se matan a las células sanas. "Una vez que hemos identificado a través de radares o medios tecnológicos dónde están ellos (el EPP), tendremos que tirar bombas o granadas, y cuando los matemos a ellos, van a tener que morir gente inocente" ("Bombas para poner punto final al EPP”, 2015) ${ }^{13}$. La Asociación Rural del Paraguay (ARP), integrada por los principales ganaderos del país, en cuyas manos se encuentran

12 Las autoridades castrenses y policiales no dan a conocer a la cantidad exacta de integrantes de la FTC. 13 La Senadora Mirta Gusinky, cuya hija, Cecilia Cubas, fue hallada muerta en una ciudad del área metropolitana de Asunción en el 2005 luego de aproximadamente cinco meses de secuestro, que el Estado y los medios de comunicación atribuyen al "EPP", fue también la legisladora que había señalado que el mismo campesino que labra la tierra puede ser un integrante de la "guerrilla". El "EPP", tal como se explicó en este trabajo, irrumpió en la escena pública recién en marzo del año 2008 en el área rural del norte paraguayo, a alrededor de quinientos kilómetros de la capital paraguaya, y es según la versión hegemónica una "guerrilla" rural y no urbana. El ex - esposo de Gusinky, Raúl Cubas Grau, fue presidente de la república durante el breve período de agosto de 1998 a marzo de 1999, cargo al que renunció ante la inminencia de su destitución a través de un juicio político. 
concentradas las más grandes extensiones de tierras, propuso en el 2017 al Senado que se flexibilice la legislación y se permita una mayor deforestación para encontrar a los integrantes del "EPP". "Dicen que estos maleantes se esconden en los montes, entonces tratemos de dar una explotación más intensiva a los montes (...) para que estas personas que están ocasionando un gran daño al país no lo sigan haciendo" (Luis Villasanti, presidente de la ARP, en "ARP plantea deforestar para combatir al EPP", 2017) ${ }^{14}$.

\section{Voces divergentes que irrumpen en momentos de crisis}

El 02 de setiembre del 2020 dos "integrantes" del "EPP" fueron abatidas en un supuesto enfrentamiento con la Fuerza de Tarea Conjunta (FTC). El presidente de la república Mario Abdo Benítez voló inmediatamente desde Asunción hasta el departamento de Concepción, se hizo presente en el lugar en que se produjo el hecho, posó ante las cámaras junto a integrantes de la FTC y celebró la noticia de la muerte de dos "combatientes" del "EPP" en un momento en el que su gobierno se encontraba bastante cuestionado por escándalos de corrupción ("Marito recibe un balón de oxígeno", 2020).

Las víctimas del supuesto

\footnotetext{
14 Datos del censo agropecuario del 2008, el último llevado a cabo en Paraguay, indicaban que ese año solo el $13 \%$ del territorio de todo el departamento de Concepción, el segundo más extenso de la región oriental de Paraguay, donde irrumpió por primera vez el "EPP", se encontraba cubierto por bosques. El $81 \%$ de toda la superficie boscosa se encontraba en propiedades de mil y más hectáreas, es decir en los más grandes establecimientos pertenecientes a menos del $1 \%$ de todos los propietarios de tierras. En el $97 \%$ de todas las propiedades, las que tienen menos de 20 hectáreas, pertenecientes a familias campesinas, solo se encontraba el 3,5\% de toda la superficie de bosques (Pereira, 2014), en realidad mechones de montes. Es decir, si el "EPP" opera "desde el bosque" que debe ser derribado según la ARP, no lo hace desde territorio campesino. A juzgar por las publicaciones periodísticas relacionadas a la deforestación en el norte paraguayo es de esperarse que en la actualidad la cobertura boscosa sea aún menor a la registrada por el censo del 2008.
}

enfrentamiento resultaron ser dos niñas de nacionalidad argentina de 11 años de edad ("Documentos de identidad revelan que niñas abatidas”, 2020). Las niñas habían viajadoa Paraguayparavisitarasusfamiliares y no habían podido retornar a la Argentina debido a las restricciones impuestas por el aislamiento establecido para hacer frente a la pandemia del COVID19. La madre denunció que las niñas fueron ejecutadas y no muertas en un enfrentamiento como aseguraron las autoridades paraguayas de seguridad ("Niñas fueron tomadas vivas, torturadas y ejecutadas”, 2020). La situación generó la protesta del gobierno argentino que solicitó el pronto esclarecimiento del hecho. El embajador de Argentina en Paraguay rechazó, en el mismo sentido del comunicado del gobierno de su país, las expresiones del comandante de la FTC, Héctor Grau.

También se condena fuertemente las expresiones del general Grau, en función de que Argentina es un lugar de formación y de reclutamiento de quienes van a ser integrantes del Ejército del Pueblo Paraguayo (EPP). Imagínense una situación al revés y distinta, que dos ciudadanas paraguayas menores hayan sido abatidas en Argentina en determinadas circunstancias, cuál sería la reacción que tendría el Gobierno y el pueblo paraguayo. (Domingo Peppo, embajador argentino en Paraguay, en "Gobierno argentino exige a Paraguay el esclarecimiento de muertes de niñas", 2020)

La muerte generó el repudio de la Comisión Interamericana de Derechos Humanos ("Organismo internacional repudia muerte de las dos niñas” 2020). El representante en América del Sur de la Alta Comisionada de las Naciones Unidas para los Derechos Humanos exigió la realización de una investigación imparcial y sin demora ("ONU exige esclarecer muerte de 
niñas", 2020). La Comisión de Derechos Humanos del Parlamento del Mercosur (Parlasur) resolvió llevar adelante una indagación independiente para esclarecer las circunstancias de la muerte de las niñas ("Parlasur también investigará muerte de las dos niñas”, 2020). La Cámara de Diputados de Argentina también exigió una exhaustiva y urgente investigación a las autoridades paraguayas ("Congreso de Argentina pide investigación”, 2020).

El og de setiembre del 2020, en horas de la tarde, se desarrollaba una sesión reservada de la Cámara de Senadores en la que representantes de la FTC y otras autoridades nacionales fueron convocadas para brindar detalles sobre el operativo que tuvo lugar la semana anterior y en la que resultaron muertas dos niñas. El carácter reservado de la sesión fue bastante cuestionado por sectores sociales y políticos que expresaban abiertamente su desconfianza sobre el operativo, el cual se pudo haber tratado de una abierta ejecución y no un enfrentamiento. Por una ajustada mayoría, tan solo un voto de diferencia ${ }^{15}$, el Senado aprobó sesionar a puertas cerradas tal como lo había solicitado el propio presidente de la república, principal responsable político de las actuaciones de la FTC.

En el momento en que tenía lugar el encuentro reservado, la Fiscal General del Estado, Sandra Quiñónez, se puso en contacto telefónico con el presidente del Congreso, Oscar Salomón, a quien informó que el ex - vicepresidente de la república, Óscar Denis Sánchez, fue secuestrado en el norte paraguayo. La sesión fue levantada de inmediato ("Secuestran al exvicepresidente liberal Óscar Denis”, 2020). A tan solo dos días del secuestroy pese a todo el despliegue militar y policial, a pocos kilómetros en que fue capturado el ex - vicepresidente junto a un trabajador suyo, el "EPP” dejó un

1519 senadores votaron a favor del carácter secreto de la sesión mientras que 18 para que sea abierta y pública ("Defienden reunión reservada", 2020). panfleto que se encontraba contenido en una bolsa de plástico atada a un portón de la estancia del ex -político ("Hallan panfletos del EPP en estancia de Denis", 2020). En el papel dejado el supuesto grupo insurgente hizo conocer sus exigencias. Una de ellas ordenaba a la familia del secuestrado la entrega de paquetes conteniendoalimentos, medicamentos, juguetes, insumos agrícolas y otros a 40 comunidades, campesinas e indígenas, por un valor de dos millones de dólares, cincuenta mil dólares a cada una, además de exigir la liberación de dos de sus supuestos líderes que desde hace años se encuentran en la cárcel ("EPP pretende intercambiar rehenes por secuestradores presos", 2020).

Denis fue supuestamente secuestrado por una brigada indígena del "EPP" ("Brigada indígena del EPP se atribuye secuestro", 2020). Los líderes de las 21 comunidades indígenas del departamento de Concepción señalan que del "EPP” saben en realidad lo que escuchan en la radio, es decir, nunca constataron la operación de una "guerrilla" en su territorio. Líderes de 14 comunidades originarias Paĩ Tavyterã de Amambay, departamento vecino de Concepción, aseguran lo mismo, recalcando que el reclutamiento del grupo "guerrillero" es poco probable. Indican que luego del secuestro de Denis fue la primera vez que se les consultó sobre la supuesta insurgencia. Otra de las exigencias del "EPP" a los familiares del ex - vicepresidente fue mostrar un video de contenido propagandístico en el que se observa un supuesto entrenamiento de los "combatientes" del "EPP" y en el que se presenta a una nueva célula, la "Brigada Indígena" del "EPP". La exigencia fue cumplida por la familia que entregó a la prensa el material audiovisual ("EPP facilita material audiovisual a familiares de Óscar Denis", 2020).

Desconozco, y eso que en
mi organización tenemos 14
comunidades y hablamos de la
realidad de cada una, en un aty


guasu $^{16}$, cada 3 meses (...) Yo recorro las comunidades y converso con los padres de familia y con las chicas y muchachos para que no se metan en nada ilegal o malo (...) no dejamos ingresar a extraños a nuestros asentamientos (...) Los Paĩ Tavyterã somos muchos, y mis paisanos no andan como dicen que son los del EPP. Conozco cada comunidad (Luis Arce, líder Paĩ Tavyterã en "Líderes están sorprendidos por la supuesta brigada indígena del EPP”, 2020).

La comunidad indígena del pueblo Paĩ Tavyterã, de la que es integrante el trabajador que fue secuestrado junto al ex - vicepresidente de la república ${ }^{17}$, expresó su repudio a las actuaciones del "EPP" indicando que sus integrantes solo buscan dinero y violencia ("La comunidad Pai Tavytera desmiente y repudia al EPP”, 2020). Por su parte setenta y cinco comunidades indígenas rechazaron los paquetes de alimentos y otros insumos que el "EPP" obligó a los familiares de Denis a entregarles ("Unas 75 comunidades indígenas del Chaco rechazan víveres del EPP”, 2020). También lo hicieron las comunidades campesinas del norte paraguayo ("Campesinos de Arroyito rechazan víveres por ser producto de extorsión del EPP”, 2020).

Por lotanto nosotros, como dirigentes, rechazamos categóricamente. No estamos diciendo con eso que nuestra gente no necesita víveres. Somos conscientes de que acá hay muchas necesidades (...) Nosotros

16 Aty guasu: expresión en guaraní que hace referencia a una asamblea comunitaria

17 El joven indígena Adelio Mendoza fue liberado cinco días después de una intensa presión ejercida por los y las integrantes de su comunidad, quienes por su propia cuenta y desarmados fueron a buscar a ambos secuestrados ante el escaso interés demostrado por los efectivos de la Fuerza de Tarea Conjunta ("Indígenas ingresaron al monte en busca de los secuestrados", 2020). El ex - vicepresidente de la república no tuvo la misma suerte que su trabajador y siguió retenido por los secuestradores. recomendamos a nuestra gente no aceptar en honor a la dignidad de la gente trabajadora, especialmente de esta comunidad. Por otro lado manifestamos nuestra solidaridad con la familia del señor Óscar Denis. Él es una persona conocida, fue el primer gobernador del departamento de Concepción (...) también con el compañero Adelio Mendoza (...) Ante nuestra gente y la opinión pública dejamos en claro nuestra postura que no estamos de acuerdo con la recepción de este tipo de asistencia que no sea del Estado paraguayo (...) No descartamos tomar otras medidas para repudiar estos hechos y seguir reclamando nuestros derechos como corresponde, como comunidad campesina. (Marciano Jara, líder de la comunidad campesina de Arroyito, departamento de Concepción, 14 de septiembre de 2020)

De manera contraria a lo asegurado por algunos analistas, líderes políticos, autoridades de instituciones de seguridad y de otras del Estado paraguayo, periodistas, empresarios, grandes terratenientes y otros, el rechazo de la población a la manera de actuar del "EPP" en la misma zona en la que supuestamente opera, resulta ser notablemente claro.

Venga de donde venga no estamos de acuerdo con el terrorismo. Lo rechazamos rotundamente. Además como comunidad no estamos de acuerdo con el ofrecimiento extorsivo que realiza porque tenemos dignidad como personas, como campesinos. Nosotros somos trabajadores honestos. Por esa razón no estamos de acuerdo con ese tipo de extorsión que nos están ofreciendo. Nosotros decimos que no podemos aceptar esto como comunidad (...) No necesitamos asistencialismo porque el asistencialismo no nos lleva a ninguna parte. Este asistencialismo 
[del EPP] no es diferente al otro asistencialismo que conocemos [asistencialismo político] (...) Pedimos disculpas a los familiares de Óscar Denis y Adelio Mendoza porque no podremos aceptar esto. (Juan Ángel Díaz, dirigente de la comunidad campesina norteña Arroyito, 13 de septiembre de 2020)

No fue esa la primera vez que los pobladores y pobladoras de la comunidad campesina de Arroyito rechazaron las acciones del "EPP" y las acusaciones que les relacionan con el hipotético grupo insurgente. En el 2016, tras el atentado en el que murieron ocho jóvenes militares que fueron emboscados en un camino vecinal de la comunidad cuando viajaban en un camión, los y las habitantes declararon a la prensa su malestar por ser vinculados permanentemente con el supuesto grupo guerrillero ("Pobladores de Arroyito están cansados de ser relacionados con el EPP”, 2016).

En los últimos tiempos ni a nuestros hijos que van a buscar trabajos en las estancias se les da un empleo. Nuestra situación es muy mala. No nos dan trabajo porque somos de Arroyito (...) Los patrones les dan trabajo a los brasileños en las estancias, les pagan bien. A ellos no les tienen miedo, a nosotros sí. A nosotros los campesinos que trabajamos honestamente no nos dan un empleo cuando vamos a buscarlo. Solo nos permiten trabajar en aquello que nadie quiere hacer (...) Se genera miedo sobre nosotros y nuestra comunidad, aquí no hay nadie [nadie del "EPP"]. Nosotros recorremos todos los días, los militares están en varios puntos, nos detienen tres a cuatro veces al día en el camino, nos piden documentos (...) $\mathrm{Si}$ por el camino transitaran ya hace rato hubiesen tomado a todos los integrantes del EPP (Pablo Ponce, poblador de Arroyito, o3 de septiembre de 2016).

La consulta periodística a la población sobre las circunstancias de la masacre que mató a ocho militares en la zona de Arroyito recibió como respuesta de una pobladora, residente en un área cercana en que se produjo el atentado, el cuestionamiento al relato de la prensa sobre los hechos de violencia ocurridos en el norte paraguayo.

Nos sentimos indignadas, en nuestra comunidad existe gente buena, gente trabajadora (...) Muchas veces la prensa transmite información en la que se nos acusa y nos afecta. Nosotros queremos defender nuestra dignidad como seres humanos (...) tenemos nuestra escuela que construimos con nuestro propio esfuerzo. Soy integrante de la comisión, luchamos haciendo y vendiendo tortillas para comprar insumos de limpieza para la escuela de nuestros hijos, tenemos nuestro templo donde nos reunimos y que hemos edificado con nuestro esfuerzo (...) Es bueno escuchar las dos campanas (...) Son los pobres los que mueren (Pobladora de Arroyito, o4 de septiembre de 2016).

Lo anterior, la muerte de personas pobres en manos de la "guerrilla", lo reconoce incluso una de las principales figuras periodísticas del diario ABC Color, indicando que definitivamente la mayor parte de las personas asesinadas por el "EPP" en todos estos años no son "oligarcas", una definición esgrimida por la "guerrilla" para justificar sus muertes y secuestros (Rehnfeldt, 2020). La comunidad campesina de Arroyito hizo escuchar su voz el 02 de setiembre del 2016 durante una concurrida movilización. Numerosas personas marcharon a través de la ruta hasta llegar al punto en el que pronunciaron su palabra, "hicieron escuchar su campana”. Expresaron su solidaridad con las familias de los ocho jóvenes militares asesinados en una emboscada atribuida oficialmente al "EPP”. 
¡No me puedo callar! ¡A los 88 años sigo al lado de ustedes! (...) ¡Siento en el alma la muerte de esos ocho hombres! (...) ¡Esos que vienen a ensuciar el nombre de la patria se hacen llamar autoridades! ¡Vienen a ensuciar el nombre de nuestro pueblo! (...) ¡Por dinero se venden! (...) i¿Por qué los jefes no se ponen al frente y dan su vida?! (...) ¡Fueron muertos ocho inocentes! (...) ¡Se hacen llamar autoridades! ¡Son cobardes! ¡Deben ser ellos quienes primero den sus vidas y luego los soldados! (Pobladora de Arroyito, o2 de septiembre de 2016).

Las circunstancias de la muerte de 8 militares, producida momentos en que sectores sociales y políticos promovían la derogación de la ley que posibilitó la participación de las Fuerzas Armadas en la seguridad interna y la consecuente militarización de la zona norte de Paraguay a partir del año 2013, llamó bastante la atención de los pobladores de Arroyito.

Denunciamos en esta movilización la muerte de ocho soldados de la patria. Nos llama la atención que los asesinados sean de rango inferior, soldaditos, además de la manera en que ocurrió el hecho. Analizamos y no sabemos qué respuestas darle. La gente se está movilizando hoy para denunciar todo hecho de violencia (...) Las organizaciones sociales siempre hacen sus peticiones en forma pacífica (...) Nosotros estamos en todo momento en desacuerdo con la violencia. Somos organizaciones que trabajamos a favor del desarrollo, predicamos a favor de la vida (Francisco Jara, o2 de septiembre de 2016).

La versión mediática y oficial ha señalado de manera recurrente que el "EPP" tendría unas pocas decenas de “combatientes". Se estima que la "guerrilla" estaría compuesta por unas veinte o treinta personas según la explicación recurrente de los responsables de las instituciones de seguridad. Tras la muerte de las dos niñas argentinas en un supuesto enfrentamiento con la FTC a principios de septiembre del 2020, el jefe de Antisecuestros de la Policía Nacional incluso llegó a afirmar que ante el fracaso de los "cabecillas" del "grupo armado" para reclutar a nuevos integrantes, recurren a "ideologizar" y a incorporar a sus propios hijos al grupo "subversivo". Esto lo afirmó el jefe policial porque las niñas asesinadas son parientes de personas sindicadas como líderes de la "organización armada" ("EPP ideologiza a niños para luego utilizarlos en primera línea”, 2020). Sin embargo cuando se habla del "EPP" se hace alusión al involucramiento del campesinado norteño.

Nos meten a todos en una misma bolsa (...) Antes del golpe de Estado que derrocó al dictador Alfredo Stroessner en 1989 ya empezó la lucha para conquistar el latifundio en el que hoy está asentada la comunidad de Arroyito (...) En Arroyito se realizó la primera ocupación de tierras luego de la caída de la dictadura. Desde entonces se ha estigmatizado a Arroyito. Nos tildaban entonces de comunistas, ese era el estigma entonces (...) Ahora nos duele que nuevamente que ante la ocurrencia de hechos de violencia se nos involucre a todos, eso nos duele, eso nos pesa (...) Estos hechos afectan la vida misma. Nos involucran en esto a todos los que soñamos con un mañana mejor no solo para nuestros hijos sino para la comunidad, el departamento y por qué no para el país. Nos sentimos mal y nos molesta todo esto (...) A donde vayamos quienes somos de Arroyito somos calificados como integrantes del EPP. Eso es triste, nosotros no vinimos a estas tierras para eso. Vinimos para construir una comunidad con pobladores que 
produzcan alimentos en medio de la felicidad. Esa es la característica de la agricultura familiar campesina, la producción de alimentos (...) Eso es vida. (Juan Cuevas, dirigente campesino de Arroyito, o4 de septiembre de 2016).

El mayor temor de los pobladores y pobladoras de las comunidades campesinas es la acusación sin prueba alguna en contra suya, lo que en la práctica se traduce en detenciones arbitrarias.

Nos llama la atención también la expresión de algunos políticos que nos meten a todos en la misma bolsa al señalar que las organizaciones sociales, el Frente Guasu' ${ }^{18}$ y la Pastoral Social son el brazo logístico del EPP. A nosotros eso nos llama la atención y nos molesta porque no tienen pruebas para acusarnos de eso (...) Como organización nuestra postura es seguir luchando siempre y denunciar toda clase de injusticias. En estos momentos estamos en zozobra, estamos en zozobra por las expresiones de esos políticos, incluso autoridades de turno como el ministro del Interior (...) Nos preocupa aún más porque como evidencia presentan el logo de nuestra organización. (Francisco Jara, o2 de septiembre de 2016)

La población rural siempre se encuentra en la mira de las fuerzas estatales de seguridad en el marco de la búsqueda de integrantes del "EPP". Quienes viven en el norte paraguayo recordaron durante una audiencia pública realizada en el parlamento en octubre del 2016, donde se abordó la derogación de la ley que posibilitó la participación de las Fuerzas Armadas

18 Coalición política de tendencia progresista con representación parlamentaria, liderada por el ex presidente de la república Fernando Lugo. en la seguridad interna y la consecuente militarización del norte paraguayo a partir del $2013^{19}$, que el mecanismo aplicado en la actualidad en la persecución de la "guerrilla" es similar al desarrollado durante la dictadura stronissta ${ }^{20}$.

A mi padre se lo persiguió por formar parte de una organización cristiana. Cuando era niña me decían que a mi padre lo lanzarían al vacío desde un avión (...) Ahora por denunciar irregularidades me señalan como parte del EPP, por denunciar esto. Me intervinieron el teléfono $y$ allanaron mi casa en el 2012. Acá está la orden de allanamiento. Por eso digo que ustedes los tres poderes del Estado son también cómplices, directa o indirectamente, porque ustedes hacen las leyes y las ponen en manos de personas que van y aplican sobre personas pobres $y$ defienden a los poderosos corruptos, enriqueciéndose a costa de la ley. En vez de defender los derechos de la gente, la Fuerza de Tarea Conjunta va defender al ganado (...) siempre sobrevuelan la zona con helicópteros, las ambulancias se pasan recorriendo las rutas, las camionetas cargadas de militares se pasan recorriendo y nunca encuentran al EPP (...) Se mata a personas inocentes, se mata a alguien y se dice que es del EPP o se le apresa. Mientras tanto quedan muchos niños sufriendo (...) Se les

19 La audiencia pública contó en Asunción con la participación de más de 200 personas entre quienes se encontraban dirigentes de organizaciones campesinas del norte paraguayo, organizaciones sociales nacionales, defensores/as de derechos humanos y víctimas de la represión estatal en el marco de la lucha contra el "EPP". La audiencia debía llevarse a cabo en la misma zona norte del Paraguay en la primera semana de setiembre del 2016 pero una semana antes, el 27 de agosto de ese año, se produjo la masacre en la que murieron ocho jóvenes militares en el departamento de Concepción.

20 La dictadura de Alfredo Stroessner gobernó el Paraguay durante 35 años, desde 1954 a 1989. 
ordena a los intervinientes a patear las puertas de las casas y llevar todo lo que encuentren (...) Dense cuenta de lo que nosotros sufrimos, pónganse en nuestro lugar (...) Lo único que vale es lo que dice el fiscal. El fiscal da autorización a los policías y militares para que actúen de forma brutal. Nos hacen tener miedo. En tiempo de Stroessner tenía miedo, ahora vuelvo a tener (...) En el 2008 volví al norte en busca de paz; a dos años de volver allanaron mi casa porque decían que yo era del EPP. ¿Existe realmente el EPP?, porque ¿dónde está? La Fuerza de Tarea Conjunta sobrevuela todo el día y no encuentra a los integrantes del EPP (Adelfa Gómez, 18 de octubre de 2016).

Cuatro años después de la declaración realizada por la pobladora del norte paraguayo en una audiencia pública en el Congreso Nacional, la búsqueda del "EPP" continuaba en el norte paraguayo. Más de un mes después del secuestro del ex - vicepresidente Ôscar Denis, la Fiscalía imputó a un grupo de seis personas por su participación en el plagio, imputación que fue admitida por un juez, quien dijo que citaría a los supuestos secuestradores a través de los medios de comunicación masiva considerando que estarían "en algún lugar del bosque en el norte del país" ("Juez procesa a captores de Óscar Denis", 2020). Según el relato realizado en una conferencia de prensa por el fiscal Federico Delfino, el Ministerio Público ya había determinado con exactitud a finales de la primera quincena de octubre del 2020, además de la identidad de los captores, la manera en que ocurrieron los hechos.

Tenemos $100 \%$ de seguridad que estas personas son las que retuvieron el 9 de setiembre a don Óscar Denis, que fueron los que dejaron esa prueba de vida, esas exigencias el día 11 (de setiembre) y que liberaron a Adelio Mendoza (...) Conforme al trabajo que está realizando la Fiscalía Antisecuestro, tenemos información que dentro del monte (...) fue ingresado el señor Óscar Denis, donde se establecieron dos lugares de cautiverio. Tenemos información de cómo fueron alimentados, quiénes $y$ de que recibieron un buen trato en todo momento por parte de estas personas. (Federico Delfino, fiscal de la Unidad Antisecuestro, 14 de octubre de 2020, en "Fiscalía identifica e imputa”, 2020)

En la noche del 20 de noviembre de 2020 , según la versión oficial de las instituciones de seguridad, fueron abatidos tres integrantes del "EPP" que habrían secuestrado a Óscar Denis ("Confirman tres abatidos del EPP en Concepción”, 2020) ${ }^{21}$. Los tres hombres muertos, según la Fiscalía, son miembros importantes de la supuesta organización armada ("Abatidos son personas "importantísimas" del grupo criminal", 2020). A pesar del éxito atribuido a la operación en que murieron tres "guerrilleros", la anterior imputación y la certeza de las autoridades sobre lo ocurrido, finalmente no se logró tener pistas sobre el cautiverio del ex - vicepresidente, lo que decepcionó notablemente a sus familiares. "No tenemos información, ellos (FTC) no nos dicen nada, entonces concluimos que no saben dónde está mi papá" (Beatriz Denis, hija de Óscar Denis, 23 de noviembre de 2020, en "Concluimos que no saben dónde está mi papá”, 2020). La falta de resultados pese a los anuncios triunfalistas le llevó a decir al ministro del Interior, Euclides Acevedo, que el gobierno está haciendo un papelón ("Estamos haciendo

\footnotetext{
21 Dos de los abatidos recibieron impactos de bala desde más de cien metros de distancia, mientras que uno de ellos recibió el disparo que lo mató desde casi cuatrocientos metros. El tiroteo se produjo en horas de la noche. Los supuestos guerrilleros fueron divisados por integrantes de las fuerzas de seguridad mediante equipos de alta tecnología. Oficialmente se trató de un enfrentamiento entre la "guerrilla" y la FTC ("fueron tiros de muy larga distancia", 2020; "Así ocurrió el enfrentamiento", 2020).
} 
un papelón", 2020), lo que para una de las hijas de Denis significa que el gobierno, en términos futbolísticos, está perdiendo "dos mil a cero" ("Hijas de Óscar Denis fustigan al gobierno", 2020).

\section{Conclusiones}

A lo largo de más de una década de la irrupción de la violencia de una supuesta guerrilla y la activación de su combate por parte de las fuerzas estatales, el relato de los hechos violentos fue hegemonizado por la prensa empresarial que construyó su versión sobre la base de afirmaciones de agentes del Ministerio Público, instituciones de seguridad, líderes políticos y empresariales. La versión hegemónica de la realidad del norte paraguayo constituyó además a un sujeto violento, el "campesino guerrillero", el que de "día es agricultor" y a la noche se transforma en "combatiente" del "EPP".

El sujeto al que se le ha atribuido la violencia o su colaboración con la misma, a veces de manera directa y otras de manera indirecta, ha resultado ser el mismo que ha cuestionado desde sus organizaciones los impactos del modelo de desarrollo del norte paraguayo. Es un sujeto subversivo para el agronegocio, sector económico al que ha puesto en jaque con sus denuncias que fueron tenidas en cuenta por el Estado paraguayo en los inicios de la expansión sojera en el departamento de Concepción.

Exigir el respeto de la producción agro-empresarial a las leyes ambientales y reivindicar el acceso a una fracción de tierra se constituyeron en sinónimos de vinculación con la "violencia guerrillera" desdeel primer atentado del "EPP" en marzo del 2008. Dicho atentado se produjo en momentos en que la comunidad campesina de Kurusu de Hierro había logrado la atención de varias instituciones estatales que dieron la razón a su reclamo y días antes de una negociación clave que pudo haber culminado en el traspaso a familias campesinas norteñas de tierras fiscales que estarían irregularmente incorporadas en el establecimiento en que hizo su primera aparición el "EPP”.

El mismo propietario de ese establecimiento denunció varias veces a sus vecinos campesinos de delitos que no pudieron probarse y que llevó a que los jueces desestimen esas denuncias. Los líderes de la comunidad campesina cuyos integrantes fueron acusados varias veces dijeron que en realidad esas acusaciones formaban parte de una represalia por las sistemáticas denuncias que realizaban contra la fumigación irregular de agroquímicos en los cultivos de soja del terrateniente vecino.

Pese a mostrarse partidario de la reivindicación campesina, el "EPP" terminó frustrando la lucha de quienes invocó como representados en su primer panfleto y en el que prometió cobrar venganza contra la fumigación irregular de agroquímicos en monocultivos del agronegocio, además de exigir tierra para la población campesina. La amenaza y la acción violenta del supuesto grupo insurgente, sumada a la apropiación del discurso de las organizaciones campesinas, fortalecieron la línea editorial de los principales medios de comunicación de Paraguay sobre la actitud violenta del campesinado.

Fiscales, policías, militares, líderes políticos, empresarios, periodistas y otros actores vinculados a sectores hegemónicos apuntaron con sus acusaciones a la población campesina, cuya versión fue abiertamente desconocida, prácticamente silenciada. Su voz sin embargo se escuchó de manera vigorosa ocho años después del primer atentado del "EPP". Fue luego de la masacre ocurrida en agosto del 2016 en que fueron asesinados, supuestamente por la "guerrilla" ocho jóvenes militares. Su voz afloró desde el silencio en un momento de crisis de manera contestataria al exceso de discursos oficiales (Pollak, 2006). Los campesinos del norte paraguayo expresaron en la ocasión a la prensa su sentimiento de hartazgo sobre el vínculo que se le atribuye con el supuesto grupo insurgente cuyos muertos pertenecen a la clase social por la que supuestamente luchan. 
Cuatro años después de la primera irrupción de la voz del campesinado norteño en el espacio público respecto a la violencia "insurgente", en el 2020 otra crisis ocasionada por la muerte de dos niñas a manos de las fuerzas estatales de seguridad, primero, y el secuestro de un ex-vicepresidente de la república, después, posibilitó la configuración de condiciones para que la población rural haga aún más claro su posicionamiento sobre las actuaciones de la "guerrilla". El "EPP" exigió a cambio de liberar al ex-vicepresidente la repartición de víveres y otros insumos a familias campesinas e indígenas por un valor de dos millones de dólares. La reacción fue inmediata. Tanto comunidades campesinas como indígenas rechazaron la oferta por considerarla producto de un chantaje que ofende su dignidad.

Considerada una organización revolucionaria con apoyo popular según algunos, el "EPP" ha demostrado en realidad con la exigencia de repartición de víveres su verdadero límite revolucionario. Llama la atención que una de las exigencias para liberar al ex - vicepresidente de la república secuestrado por parte de un grupo "insurgente", que desde su primera aparición "exigió" tierras en su panfleto, no haya sido justamente la entrega de terrenos rurales a familias campesinas en la zona con uno de los niveles más altos de desigualdad en el acceso a la tierra a nivel mundial.

El monto de 2 millones de dólares exigido por el "EPP" para entregar paquetes de alimentos y otros insumos a familias campesinas e indígenas es fácilmente el presupuesto de un programa de asistencia social de un gobierno local del norte paraguayo, cuya implementación no significa de ninguna manera el mejoramiento de la calidad de vida de la población y mucho menos la modificación de la estructura de la realidad social. Es, como dicen los líderes de organizaciones campesinas de Concepción, un asistencialismo más cuyo nulo impacto conocen muy bien.

\section{Referencias}

ABC. (o9 de setiembre de 2020). $A B C$. Brigada indígena del EPP se atribuye secuestro de Oscar Denis. https://www. abc.com.py/nacionales/2020/o9/o9/ brigada-indigena-del-epp-se-atribuyesecuestro-en-el-norte/

ABC. (o9 de setiembre de 2020). Defienden reunión reservada porque se hablará sobre inteligencia de la FTC. https://www.abc.com.py/ nacionales/2020/o9/o9/defiendenreunion-reservada-porque-se-hablarasobre-inteligencia-de-la-ftc/

ABC. (13 de setiembre de 2020). Campesinos de Arroyito rechazan víveres por ser producto de extorsión del EPP. https://www.abc.com.py/ nacionales/2020/09/13/campesinosde-arroyito-rechazan-viveres-por-serproducto-de-extorsion-del-epp/

ABC. (2 de mayo de 2017). ARP plantea deforestar para combatir al EPP. https://www.abc.com.py/edicionimpresa/politica/arp-planteadeforestar-para-combatir-alepp-158978o.html\#: :text=E1\%20 presidente $\% 2$ od e \% 2 ola \% 2 o Asociaci\%C3\%B3n,del\%2oPueblo\%20 Paraguayo\%2o(EPP)

ABC. (21 de noviembre de 2020). Confirman tres abatidos del EPP en Concepción. https://www.abc.com.py/tv/abcnoticias/2020/11/21/confirman-tresabatidos-del-epp-en-concepcion/

ABC. (23 de febrero de 2009). Comisaría en la conflictiva Kurusu de Hierro. http:// www.abc.com.py/edicion-impresa/ interior/comisaria-en-la-conflictivakurusu-de-hierro-1149496.html

ABC TV Paraguay. (11 de setiembre de 2020). EPP facilita material audiovisual a familiares de Óscar Denis [Video]. Youtube. https://www.youtube.com/ watch?v=RrYJBqQhiW8

$A B C$. (03 de setiembre de 2020). EPP ideologiza a niños para luego utilizarlos en primera línea, afirman. https://www. abc.com.py/nacionales/2020/09/03/ epp-ideologiza-a-ninos-parautilizarlos-en-primera-linea-afirman/ 
ABC. (o6 de setiembre de 2020). ONU exige esclarecer muerte de niñas en operativo contra EPP. https://www.abc.com. py/nacionales $/ 2020 / 09 / 06 /$ onuexige-esclarecer-muerte-de-ninas-enoperativo-contra-epp/

ABC. (o7 de diciembre de 2020). Hijas de Oscar Denis fustigan al Gobierno y dicen que el EPP gana "2.00o a o". https://www.abc.com.py/ nacionales/2020/12/07/hijas-de-oscardenis-fustigan-al-gobierno-y-dicenque-el-epp-les-gana-2000-a-o/

ABC. (08 de setiembre de 2020). Parlasur también investigará muerte de las dos niñas en el operativo de la FTC. https://www.abc.com.py/ nacionales/2020/09/o8/parlasurtambien-investigara-muerte-de-lasdos-ninas-en-el-operativo-de-la-ftc/

ABC. (o9 de setiembre de 2020). Secuestran al exvicepresidente liberal Óscar Denis. https://www.abc.com. $\mathrm{py} /$ nacionales/2020/09/09/eppsecuestro-al-exvicepresidente-liberaloscar-denis/

ABC. (11 de setiembre de 2020). EPP pretende intercambiar rehenes por secuestradores presos. https://www. abc.com.py/nacionales/2020/o9/11/ epp-pretende-intercambiar-rehenespor-secuestradores-presos/

ABC. (11 de setiembre de 2020). Hallan panfletos del EPP en estancia de Denis. https://www.abc.com.py/ nacionales/2020/09/11/hallanpanfletos-del-epp-en-estancia-dedenis/

ABC. (11 de setiembre de 2020). La comunidad Pai Tavytera desmiente y repudia al EPP. https://www.abc. com.py/nacionales/2020/o9/11/lacomunidad-pai-tavytera-desmiente-yrepudia-al-epp/

ABC. (13 de setiembre de 2020). Pedirán informe sobre gasto de casi US\$ 1 millón al mes de la FTC. https://www. abc.com.py/nacionales/2020/09/13/ pediran-informe-sobre-gasto-de-casius-1-millon-al-mes-de-la-ftc/
ABC. (14 de marzo de 2008). Queman tractores y galpón en estancia.

ABC. (18 de setiembre de 2020). En el IAEE se estudia que el EPP es una organización guerrilera marxistaleninista. https://www.abc.com.py/ nacionales/2020/o9/18/en-el-iaee-seestudia-que-el-epp-es-una-guerrillamarxista-leninista/

$A B C$. (23 de noviembre de 2020). EPP: Abatidos con personas "importantísimas" del grupo criminal, asegura el fiscal Delfino. https:// www.abc.com.py/73oam/anchoperfil/2020/11/23/epp-abatidos-sonpersonas-importantisimas-del-grupocriminal-asegura-el-fiscal-delfino/

ABC. (30 de setiembre de 2008). Organizaciones izquierdistas crean ambiente de terror en la zona norte.

ABC. (31 de agosto de 2013). La doble cara de los bolivarianos vernáculos. https://www.abc.com.py/edicionimpresa/editorial/la-doble-cara-de-losbolivarianos-vernaculos-613003.html

Boccia, A. (12 de setiembre de 2020). El EPP y el establishment del Norte. Última Hora. https://www.ultimahora. com/el-epp-y-el-establishment-delnorte-n2904499.html

Brubaker, R., \& Cooper, F. (2002). Más allá de identidad. Apuntes de investigación (7), 30-67.

Carbone, R. (o7 de setiembre de 2020). Paraguay: ejecución y revolución. E'a. http://ea.com.py/blogs/paraguayejecucion-y-revolucion/

Díaz, J. A. [TelefuturoInfo]. (14 de setiembre de 2020). Comunidades rechazaron víveres del EPP [Video]. Youtube. https://www.youtube.com/ watch?v=M-671ublwAo

E'a. (19 de febrero de 2015). Fiscal culpa a pobladores por ataque contra comisarías. http://ea.com.py/fiscalculpa-a-pobladores-por-ataquecontra-comisarias/

Grimson, A. (2011)-Los límites de la cultura. Siglo Veintiuno Editores. 
Grimson, A., Mereson, S., \& Noel, G. (2011). Descentramientos teóricos. En A. Grimson, S. Mereson y G. Noel (Comps.) Antropología Ahora. Debates sobre alteridad (pp.9-31). Siglo XXI Editores.

Guber, R. (2001). La etnografía, método, campo y reflexividad. Grupo Editorial Norma.

Gusinky dice que "el campesino que está labrando la tierra puede ser del EPP" (03 de octubre de 2013). E'a. http://ea.com. py/gusinky-dice-que-el-campesinoque-esta-labrando-la-tierra-puedeser-del-epp/

Hall, S. (2003). ¿Quién necesita 'identidad'? En S. Hall y P. Du Gay (Comps.) Cuestiones de identidad cultural (pp.1339). Amorrortu Editores.

Hayner, P. (2009). El reto de las comisiones de la verdad. Fondo de Cultura Económica.

Hoy. (o5 de setiembre de 2020). Organismo internacional repudia la muerte de las dos niñas abatidas en Concepción. https://www.hoy.com.py/nacionales/ organismo-internacional-repudia-lamuerte-de-las-dos-ninas-abatidas-enconcepcion

Hoy. (23 de noviembre de 2020). Beatriz Denis: "Concluimos que no saben dónde está mi papá". https://www. hoy.com.py/nacionales/beatriz-denisconcluimos-que-no-saben-dondeesta-mi-papa

Irala, A. \& Pereira, H. (2016). Violencia armada y avance de la soja en el norte del Paraguay. Conflicto social, 9 (16), 180-208. https://publicaciones. sociales.uba.ar/index.php/CS/article/ view/2170

Jara, M. [TelefuturoInfo]. (14 de setiembrede 2020). Comunidades rechazaron víveres del EPP [Video]. Youtube. https://www. youtube.com/watch?v=M-671ublwAo

La Nación. (11 de noviembre de 2020). Estamos haciendo un papelón”, dice ministro sobre secuestro de Óscar Denis. https://www.lanacion.com.py/ hoy/2020/11/11/estamos-haciendo- un-papelon-dice-ministro-sobresecuestro-de-oscar-denis/

La Nación. (13 de setiembre de 2020). Indígenas ingresaron al monte en busca de los secuestrados y el EPP. https://www.lanacion.com.py/ politica/2020/09/13/indigenasingresaron-al-monte-en-busca-de-lossecuestrados-y-el-epp/

La Nación. (14 de agosto de 2015). Bombas para poner punto final al EPP, sugiere Mirta Gusinky. https://www.lanacion. com.py/2015/o8/14/bombas-paraponer-punto-final-al-epp-sugieremirta-gusinky/

La Nación. (16 de octubre de 2020). Juez procesa a captores de Óscar Denis. https://www.lanacion.com.py/ judiciales/2020/10/16/juez-procesa-acaptores-de-oscar-denis/

La Nación. (23 de setiembre de 2011). Fiscala Ruiz asegura saber dónde están los guerrilleros.

Malamud, J. (200o). Terror y justicia en la Argentina. Responsabilidad y democracia después de los juicios al terrorismo de Estado. Ediciones de la Flor.

Martens, J. (2017). Aproximaciones a la naturaleza del EPP desde la perspectiva de la insurgencia. Novapolis, (12), 4368.

Nickson, A. (2019). Movimientos insurgentes en América Latina después de la Guerra Fría: El caso del Ejército del Pueblo Paraguayo. Novapolis, (15), 63-84.

Oberti, A., \& Pittañuga, R. (2016). Apuntes para una discusión sobre la memoria y la política de los años 6o/70 a partir de algunas intervenciones recientes. Sociohistorica, (38), 1-22. http://www. sociohistorica.fahce.unlp.edu.ar/ article/view/SHo15

Pereira, H. (2014). EPP y ACA, ¿Rótulos paramilitares? Una mirada no "asuncéntrica" sobre las reales posibilidades del desarrollo de la guerra de guerrillas en Concepción. 


\section{Novapolis, (7), 129-164.}

Pereira, H. (2016). Extractivismo armado en Concepción. "EPP”, la fantasmal guerrilla que "lucha" por la expansión del capital internacional en suelo norteño. CERI.

Pizarro Leongómez, E. (2004). Democracia asediada. Grupo Editorial Norma.

Pollak, M. (2006). Memoria, olvido, silencio. Ediciones Al Margen.

Rehnfeldt, M. (13 de setiembre de 2020). Bárbaros. $A B C$. https://www.abc.com. py/opinion/2020/o9/13/barbaros/

Sánchez, J. (2009). El campesino paraguayo es pobre porque es ignorante. El discurso legítimo de los medios escritos de comunicación y la lucha por la tierra. En M. Palau (Ed.), Criminalización a la lucha campesina (pp. 103-131). Base Is.

Segovia, D. (2010). Comunicación y democracia. El rol de los medios en la construcción del discurso político ciudadano. Base is.

SenadoTv py. (18 de octubre de 2016). Audiencia Pública - Proyecto de Ley que deroga la Ley 5036/13 [Video]. Youtube. https://www.youtube.com/ watch?v=hFnve_D6dRg

SERPAJ Paraguay. (o5 de setiembre de 2016). Movilización en Arroyito [Video]. Youtube. https://www.youtube.com/ watch?v=LRYpvR_BFUA\&t=82s

SERPAJ Paraguay. (o6 de setiembre de 2016). Francisco Jara: "Queremos tanques, pero de agua" [Video]. Youtube. https://www.youtube.com/ watch? $v=x m 9 B h F s c M H Q \& t=26 s$

TelefuturoInfo. (o3 de setiembre de 2016). Pobladores denuncian miseria y ausencia del Estado en Arroyito [Video]. Youtube. https://www.youtube.com/ atch?v=vOPg6ktxgxU\&feature $=\mathrm{emb}_{\text {_ }}$ logo

TelefuturoInfo. (o4 de setiembre de 2016). Testimonio de pobladores de Arroyito, Concepción [Video]. Youtube. https://www.youtube.com/ watch?v=9gCmFcbFJ9M
Última Hora. (o3 de setiembre de 2020). Marito recibe un balón de oxígeno de la FTC en medio de escándalos. https:// www.ultimahora.com/marito-recibeun-balon-oxigeno-la-ftc-medioescandalos-n2902986.html

Última Hora. (o3 de setiembre de 2020). Pobladores de Arroyito están cansados de ser relacionados con el EPP. https:// www.ultimahora.com/pobladoresarroyito-estan-cansados-serrelacionados-el-epp-n1021102.html

Última Hora. (o4 de setiembre de 2020). Documentos de identidad revelan que niñas abatidas por la FTC tenían 11 años. https://www.ultimahora.com/ documentos-identidad-revelanque-ninas-abatidas-la-ftc-tenian-11anos-n2903217.html

Última Hora. (o4 de setiembre de 2020). Gobierno argentino exige a Paraguay el esclarecimiento de muertes de niñas $e$ "identificación de responsables". https://www.ultimahora.com / gobierno-argentino-exige-paraguayel-esclarecimiento-muertes-ninas-eidentificacion-responsables-n2903276. html

Última Hora. (o7 de setiembre de 2020). "Niñas fueron tomadas vivas, torturadas y ejecutadas", dice madre de víctima. https://www.ultimahora. $\mathrm{com} /$ ninas-fueron-tomadas-vivastorturadas-y-ejecutadas-dice-madrevictima-n2903715.html

Última Hora. (o9 de diciembre de 2008). Grupo de izquierda se opone a la construcción de una comisaría en Horqueta. https://www.ultimahora. com/grupo-izquierda-se-oponela-construccion-una-comisariahorqueta-n17803o.html

Última Hora. (o9 de setiembre de 2020). Elevado presupuesto de la FTC no se refleja en resultados, afirman. https:// www.ultimahora.com/elevadopresupuesto-la-ftc-no-se-reflejaresultados-afirman-n2903954.html

Última hora. (11 de julio de 2017). EPP: Pagan estudios de jóvenes para captar nuevos 
miembros. https://www.ultimahora. com/epp-pagan-estudios-jovenescaptar-nuevos-miembros-n1095838. html

Última Hora. (13 de setiembre de 2020). Unas 75 comunidades indígenas del Chaco rechazan víveres del EPP. https://www.ultimahora.com/ unas-75-comunidades-indigenasdel-chaco-rechazan-viveres-delepp-n2904631.html\#: :text=Unas\%20 $75 \% 2$ o c o m un id a d e s \% 20 ind $\% \mathrm{C}_{3} \% \mathrm{ADg}$ en a $\% 2$ ode $1 \% 20$ Bajo\%2oChaco\%2orechazan \%2o la\%2oentrega,como\%2orequisito\%2o para $\% 20$ su $\% 2$ oliberaci $\% \mathrm{C}_{3} \% \mathrm{~B} 3 \mathrm{n}$

Última Hora. (14 de octubre de 2020). Fiscalía identifica e imputa a supuestos captores de Óscar Denis por terrorismo. https://www.ultimahora. com/fiscalia-identifica-e-imputa- supuestos-captores-oscar-denisterrorismo-n2909301.html

Última Hora. (15 de setiembre de 2020). Congreso de Argentina pide investigación por muerte de niñas en operativo de la FTC. https://www. ultimahora.com/congreso-argentinapide-investigacion-muerte-ninasoperativo-la-ftc-n2904926.html

Última Hora. (20 de setiembre de 2020). Líderes están sorprendidos por la supuesta brigada indígena del EPP. https://www.ultimahora.com/lideresestan-sorprendidos-la-supuestabrigada-indigena-del-epp-n2905655. html

\section{Sobre el Autor}

Hugo Pereira

Licenciado en Ciencias de la Educación con énfasis en Ciencias Sociales, Especialista y Máster en Metodología de la Investigación. Candidato a Doctor en Ciencias Sociales en la Universidad de Buenos Aires. Es autor de varias publicaciones académicas sobre la violencia registrada en el norte paraguayo 